\title{
Thermal Transport Investigation in AA7072 and AA7075 Aluminum Alloys Nanomaterials Based Radiative Nanofluids by Considering The Multiple Physical Flow Conditions
}

Adnan Abbasi ( $\square$ adnan_abbasi89@yahoo.com )

Mohi-ud-Din Islamic University

Umar Khan

Hazara University

Naveed Ahmed

HITEC University

Syed Tauseef Mohyud-Din

HITEC University

\section{Research Article}

Keywords: nanomaterials, scientific literature, nanoliquids, Aluminum Alloys

Posted Date: December 11th, 2020

DOl: https://doi.org/10.21203/rs.3.rs-123551/v1

License: (c) (1) This work is licensed under a Creative Commons Attribution 4.0 International License.

Read Full License 


\title{
Thermal Transport Investigation in AA7072 and AA7075 Aluminum Alloys Nanomaterials based Radiative Nanofluids by Considering the Multiple Physical Flow Conditions
}

\author{
Adnan ${ }^{1, *}$, Umar Khan ${ }^{2}$, Naveed Ahmed ${ }^{3}$, Syed Tauseef Mohyud-Din ${ }^{3}$ \\ ${ }^{1}$ Department of Mathematics, Mohi-ud-Din Islamic University, Nerian Sharif AJ\&K 12080, Pakistan \\ ${ }^{2}$ Department of Mathematics and Statistics, Hazara University, Mansehra 21120, Pakistan \\ ${ }^{3}$ Department of Mathematics Faculty of Sciences, HITEC University, Taxila Cantt 47070, Pakistan \\ *adnan_abbasi89@yahoo.com
}

\begin{abstract}
In recent time, variety of nanomaterials have been reported in scientific literature, among these Aluminum Alloys AA7072 and AA705 are significant with thermal, physical and mechanical characteristics. These extensively used in manufacturing of spacecraft, aircraft parts and building testing. Keeping in view the significance of nanoliquids, the analysis of methanol suspended by AA7072 and AA7075 alloys under the multiple physical flow conditions is reported. The model is successfully treated by coupling of RK and shooting algorithm and examined the results for the flow regimes by altering ingrained physical parameters. Then physical interpretation of the results discussed comprehensively.
\end{abstract}

\section{Introduction}

Thermal transport properties in colloidal suspensions over permeable plates is significant and valuable due to variety of applications in engineering, nuclear reactors, bearings lubrication and cooling, electronics and in many other industrial zone ${ }^{1}$. Two physical properties of permeable plates known as suction/injection strongly affect the heat transport characteristics and shear stresses. In 2010, Ishak reported self-similar solutions for the thermal transport over a plate under the impacts of suction/injection and convective flow condition. He pointed that self-similar solutions for steady and streamlined boundary layer flow over a permeable plate exist under the assumption that the permeable parameter and convective heat transport from the hot liquid alters with proportion of $x-1 / 2$ in which $x$ denotes the distance from the leading edge of the surface ${ }^{2}$.

The study of thermal transport in hybrid colloidal suspension over a surface with uniform suction/injection by incorporating the impacts of magnetic field in the governing hybrid model. They perceived that the heat transport upsurges for more magnetic colloidal suspension while decreasing behavior of is reported by increasing the volumetric fraction $\phi_{2}$. On the basis of presented analysis, they detected that the hybrid colloidal suspension $\left(\mathrm{Cu}-\mathrm{Al}_{2} \mathrm{O}_{3} / \mathrm{H}_{2} \mathrm{O}\right)$ is reliable for better thermal transport characteristics $^{3}$. The flow of nanofluid over chemically heated plate with suction characteristics by incorporating the Maxwell and Brinkmann correlations for thermal conductivity and density of the nanoliquid were described. Moreover, for novelty of the analysis, they retained the phenomena of viscous dissipation, radiative heat flux and chemical reaction in the constitutive model. They pointed that the heat transport rate drops for higher fraction factor and stronger Lorentz forces ${ }^{4}$.

Thermal and mass transportation in nanoliquid by plugging the influences of absorption over magnetized and radiative plate examined $\mathrm{in}^{5}$. They pointed the heat transfer characteristics in two different nanomaterials $(\mathrm{Cu}$ and $\mathrm{TiO} 2)$ suspended in water. Further, the nanoliquids velocity, thermal transport and shear stresses prevailed for $\mathrm{Cu}-\mathrm{H} 2 \mathrm{O}$ in his analysis. He reported that prevailing effects of $\mathrm{Cu}-\mathrm{H} 2 \mathrm{O}$ are due to high thermal conductance of $\mathrm{Cu}$ nanomaterial. Heat transfer study by incorporating the effects of 
porosity is significant. Keeping in view the porosity effects, Maleki et. al. ${ }^{6}$ reported the analysis of nanoliquid over porous radiative plate. They captured the flow and heat transfer behavior in four different nanoliquids depending upon four nanomaterials ( $\mathrm{Cu}$, Al2O3, SWCNTs and MWCNTs) via graphical representation. The study of streamlined boundary layer flow by considering the suction/injection property captured in ${ }^{7}$.

Heat generation or absorption analysis in flow regimes significantly alters the heat transport characteristics. Recently, Upreti et. al. ${ }^{8}$ pointed the heat transfer in silver based nanoliquid under the influence of heat generation/absorption with permeable effects over a porous surface. Furthermore, they examined the behavior of the nanoliquid velocity and temperature by altering the magnetic and Eckert parameters. In 2020, Shah et. al. ${ }^{9}$ reported the effects of Hall current, viscous and ohmic dissipation in nanoliquid squeezed inside porous sheet.

Nanomaterials are significant due to high thermal and mechanical characteristics. These materials significantly alter the properties of the nanoliquids composed by the respective nanomaterial. Among the nanomaterials, there is a material know as Aluminum alloys in which the role of aluminum is predominant. There are two principle categories of aluminum alloys which further categorized as heat treatable and non-heat treatable alloys. Aluminum alloys extensively used in the manufacturing of spacecraft, aircraft parts, building and testing. Due to better heat transport characteristics of AA7072 and AA7075 aluminum alloys, researchers analyzed various flow models composed by aluminum alloys and found fascinating behavior of the thermal transport. The heat transfer inspection in nanoliquids composed by AA7072 and AA7075 aluminum alloys by considering the effects of variable Lorentz forces reported in $^{10}$. They detected that nanoliquid composed by AA7075 alloys is better for heat transport in comparison with AA7072 composed nanoliquid.

The analysis thermal transport in magnetized AA7075 alloys by considering the electric field strength perceived $\mathrm{in}^{11}$. Three-dimensional heat transfer characteristic in hybrid colloidal model AA7072AA7075/Methanol with velocity condition examined $i^{12}$. They treated the model numerically and discussed the results for the flow regimes. Further significant results for nanofluids examined in ${ }^{13,14,15,16}$. From keen review of the literature, it is perceived that the heat transport analysis in methanol suspended by AA7072 and AA7075 aluminum alloys not reported over permeable plate. For novelty of the analysis, radiative heat flux, phenomena of heat generation/absorption, suction/injection, thermal and velocity slip effects are ingrained in the governing colloidal model. Then, numerical scheme based on shooting algorithm is adopted for mathematical treatment. Then results for the velocity, thermal transport and shear stresses for AA7072-Methanol and AA7075-Methanol are presented for suction/injection and heat generation/absorption separately. Finally, outcomes of the analysis concluded in the end. The introduction does not include a heading and should expand on the background of the topic, typically including in-text citations ${ }^{1}$.

\section{Formulation and AA7072 and AA7075 Effective Models}

The colloidal flow of AA7072-Methanol and AA7075-Methanol is taken over a permeable radiative plate in the presence of heat generation and absorption physical situation. The temperature at the surface is $\mathrm{Tw}$ while apart from the surface is $T_{\infty}$. The effects of slip condition are also considered. The velocity for suction/injection of the nanofluids is $\mathrm{v}, \mathrm{w}$ while $U_{\infty}$ is the velocity at free stream and volume rate of heat generation/absorption expressed by the following formula in which $Q_{o}$ denotes the coefficient of heat generation/absorption:

$$
Q=\left\{\begin{array}{c}
-Q_{0}\left(\tilde{T}_{\infty}-\tilde{T}\right) ; \tilde{T}_{\infty} \leq \tilde{T} \\
0 ;
\end{array}\right.
$$


Further, it is assumed that the nanomaterials AA7072, AA705 and host liquid are thermally compatible and there is no slip between them. The flow configuration of AA7072-Methanol and AA7075-Methanol is painted in Figure 1.

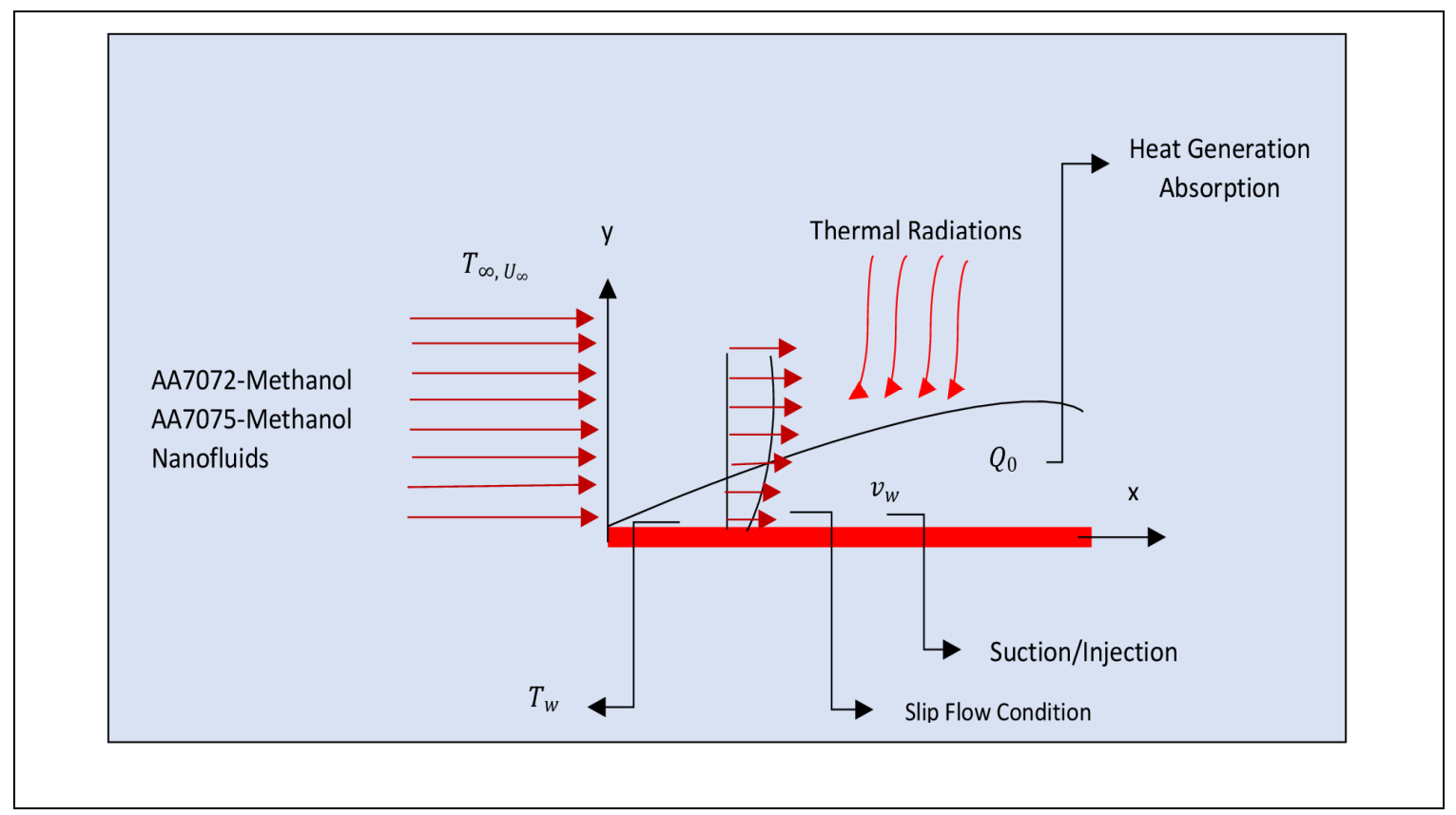

Figure 1: The flow of AA7072-Methanol and AA7075-Methanol over permeable plate

Keeping in view the assumptions and various physical situations painted in the flow configuration, the governing colloidal model by plugging the influences of slip condition, permeability, radiative heat flux and heat generation/absorption described as ${ }^{17}$ :

$\frac{\partial \widetilde{u}}{\partial x}+\frac{\partial \tilde{v}}{\partial y}=0$,

$\tilde{u} \frac{\partial \widetilde{u}}{\partial x}+\tilde{v} \frac{\partial \widetilde{u}}{\partial y}-\frac{\widetilde{\mu}_{n f}}{\widetilde{\rho}_{n f}} \frac{\partial^{2} \widetilde{u}}{\partial y^{2}}=0$,

$\tilde{u} \frac{\partial \tilde{T}}{\partial x}+\tilde{v} \frac{\partial \tilde{T}}{\partial y}-\left(\tilde{\alpha}_{n f} \frac{\partial^{2} \tilde{T}}{\partial y^{2}}+\frac{\mu_{n f}}{\left(\rho c_{p}\right)_{n f}}\left(\frac{\partial \widetilde{u}}{\partial y}\right)^{2}+\frac{Q_{0}\left(\tilde{T}-\tilde{T}_{\infty}\right)}{\left(\rho c_{p}\right)_{n f}}-\frac{1}{\left(\rho c_{p}\right)_{n f}}\left(\frac{-4 \sigma^{*} T_{\infty}^{3}}{3 k^{*}} \frac{\partial^{2} \tilde{T}}{\partial y}\right)\right)=0$,

The associated flow conditions at the permeable surface and apart from it are described in the following way:

$$
\begin{aligned}
& \tilde{u}=\lambda_{1} \frac{\partial \widetilde{u}}{\partial y} \\
& \tilde{v}=-v_{w} \quad \text { at the permeable surface } y=0 \text {, } \\
& \left.\widetilde{T}=\check{T}_{w}+\beta_{1}^{*} \frac{\partial \tilde{T}}{\partial y}\right\} \\
& \tilde{u} \rightarrow U_{\infty} \\
& \left.\tilde{T} \rightarrow \tilde{T}_{\infty}\right\} \text { apart from the suraface } y \rightarrow \infty \text {, }
\end{aligned}
$$

Where $\tilde{u}$ and $\tilde{v}$ are the velocities in horizontal and normal directions, respectively. The velocity slip, thermal slip and suction/injection are described by $\lambda_{1}, \beta_{1}^{*}$ and $v_{w}$, respectively. 
The associated invertible transformations for under consideration colloidal model are described as:

$$
\left.\begin{array}{c}
\eta=\left(\frac{U_{\infty}}{x v_{f}}\right)^{0.5} \tilde{y} \\
\beta(\eta)=\frac{\left(\widetilde{T}-\tilde{T}_{\infty}\right)}{\left(\tilde{T}_{w}-\tilde{T}_{\infty}\right)} \\
\psi=\left(x v_{f} U_{\infty}\right)^{0.5} F(\eta) \\
\tilde{u}=\frac{\partial \psi}{\partial y} \\
\tilde{v}=-\frac{\partial \psi}{\partial x}
\end{array}\right\},
$$

Where, $\beta, F, \psi$ and $\eta$ described the self-similar temperature, velocity, stream function and similarity variable, respectively.

To improve the heat transfer efficiency of AA7072-Methanol and AA7075-Methanol, following effective models are adopted:

$$
\left.\begin{array}{l}
\tilde{\alpha}_{n f}=\frac{\tilde{k}_{n f}}{\left(\rho c_{p}\right)_{n f}}=\left(\left(\varkappa_{1}-2 \phi \varkappa_{2}\right) / \varkappa_{1}+\phi \varkappa_{2}\right) /\left((1-\phi)\left(\rho c_{p}\right)_{f}+\left(\rho c_{p}\right)_{s} \phi\right) \\
\mathcal{\varkappa}_{1}=k_{s}+2 k_{f} \\
\varkappa_{2}=k_{f}-k_{s}
\end{array}\right\},
$$

Thermophysical properties for alloys AA7072, AA7075 and host liquid methanol described in Table $1^{12}$ : Table 1: Liquid phase and nanomaterials thermophysical characteristics

\begin{tabular}{|c|c|c|c|c|}
\hline \multirow{2}{*}{$\begin{array}{c}\text { Thermophysical } \\
\text { Characteristics }\end{array}$} & \multirow{2}{*}{ Unit } & Liquid Phase & \multicolumn{2}{|c|}{ Nanomaterials } \\
\cline { 3 - 5 } & & Methanol & AA7072 & AA7075 \\
\hline$\rho$ & $\mathrm{kg} / \mathrm{m}^{3}$ & 792 & 2810 & 2720 \\
\hline$c_{p}$ & $\mathrm{JK} / \mathrm{gK}$ & 2545 & 960 & 893 \\
\hline$k$ & $W / \mathrm{mK}$ & 0.2035 & 173 & 222 \\
\hline$\sigma$ & $S / m$ & $0.5 \times 10^{-6}$ & $26.77 \times 10^{6}$ & $34.83 \times 10^{6}$ \\
\hline
\end{tabular}

By implementing the described invertible transformations and nanofluids characteristics in the governing colloidal model, the following version of the model along with flow conditions is attained:

$$
\begin{aligned}
& \frac{F^{\prime \prime \prime}}{\left((1-\phi)+\frac{\phi \rho_{S}}{\rho_{f}}\right)\left(1-\phi^{2.5}\right)}+0.5 F F^{\prime \prime}=0 \text {, } \\
& \frac{\left(\left(\varkappa_{1}-2 \phi \varkappa_{2}\right) / \varkappa_{1}+\phi \varkappa_{2}\right)}{(1-\phi)+\frac{\left(\rho c_{p}\right)_{s} \phi}{\left(\rho c_{p}\right)_{f}}}\left(1+\frac{4}{3 \operatorname{Rd}\left(\left(\varkappa_{1}-2 \phi \varkappa_{2}\right) / \varkappa_{1}+\phi \varkappa_{2}\right)}\right) \beta^{\prime \prime}+0.5 \operatorname{PrF} \beta^{\prime}+\frac{\operatorname{PrEcF}^{\prime \prime 2}}{\left(1-\phi^{2.5}\right)(1-\phi)+\frac{\left(\rho c_{p}\right)_{s} \phi}{\left(\rho c_{p}\right)_{f}}}+ \\
& \frac{\gamma \operatorname{Pr} \beta}{(1-\phi)+\frac{\left(\rho c_{p}\right)_{s} \phi}{\left(\rho c_{p}\right)_{f}}}=0 \\
& \left.\begin{array}{c}
F^{\prime}=\lambda F^{\prime \prime} \\
F=f_{w}
\end{array}\right\} \text { at the } \eta=0, \\
& \beta=1+\beta^{*} \beta^{\prime} \text { ) }
\end{aligned}
$$


$\left.\begin{array}{l}F^{\prime} \rightarrow 1 \\ \beta \rightarrow 0\end{array}\right\}$ at $\eta \rightarrow \infty$

Where, heat generation/absorption corresponds to $\gamma>0$ and $<0$, respectively; suction/injection is $f_{w}>$ 0 and $<0$, respectively; velocity slip parameter $(\lambda)$, thermal slip $\left(\beta^{*}\right)$ and $E c$ is an Eckert number. These parameters are described by the following mathematical relations:

$$
\begin{aligned}
& f_{w}=2\left(\frac{x}{U_{\infty} v_{f}}\right)^{0.5} v_{w} ; \quad \text { suction/injection } \\
& \gamma=\frac{x Q_{0}}{\left(\rho c_{p}\right)_{f} U_{\infty}} \text {; heat generation/absorption } \\
& \lambda=\lambda_{1}\left(\frac{U_{\infty}^{3}}{x v_{f}}\right)^{0.5} ; \quad \text { velocity slip parameter } \\
& \beta^{*}=\beta_{1}\left(\frac{U_{\infty}}{x v_{f}}\right)^{0.5} ; \text { thermal slip parameter } \\
& R d=\frac{k_{f} k^{*}}{4 \sigma T_{\infty}^{3}} ; \text { thermal radiation parameter } \\
& E c=\frac{U_{\infty}^{2}}{\left(c_{p}\right)_{f}\left(\widetilde{T}_{w}-\tilde{T}_{\infty}\right)} ; \quad \text { eckert number } \\
& \operatorname{Pr}=\frac{v_{f}}{\widetilde{\alpha}_{f}} ; \quad \text { prandtl number }
\end{aligned}
$$

For similarity solution of the system of ODEs governing the colloidal model, parameters embedded in Eq. (15) are independent of $x$. These conditions fulfilled [17] when $Q_{0} \propto x^{-1}, v_{w} \propto x^{-\frac{1}{2}}, \lambda_{1} \propto x^{\frac{1}{2}}, \beta_{1}=x^{\frac{1}{2}}$. Therefore, $Q_{0}=A_{1} x^{-1}, v_{w}=A_{2} x^{-\frac{1}{2}}, \lambda_{1}=A_{3} x^{\frac{1}{2}}, \beta_{1}=A_{4} x^{\frac{1}{2}}$. Where, $A_{i}$ for $i=1,2,3,4$ are constants. By plugging these values in Eq. (15), we arrived with the following version of the parameters:

$f_{w}=2 A_{2}\left(\frac{1}{U_{\infty} v_{f}}\right)^{0.5} v_{w} ; \quad$ suction/injection

$$
\begin{aligned}
& \gamma=\frac{A_{1}}{\left(\rho c_{p}\right)_{f} U_{\infty}} \text {; heat generation/absorption } \\
& \lambda=A_{3}\left(\frac{U_{\infty}^{3}}{v_{f}}\right)^{0.5} ; \quad \text { velocity slip parameter } \\
& \beta^{*}=A_{4}\left(\frac{U_{\infty}}{v_{f}}\right)^{0.5} ; \text { thermal slip parameter } \\
& R d=\frac{k_{f} k^{*}}{4 \sigma T_{\infty}^{3}} \text {; thermal radiation parameter } \\
& E c=\frac{U_{\infty}^{2}}{\left(c_{p}\right)_{f}\left(\tilde{T}_{w}-\tilde{T}_{\infty}\right)} ; \quad \text { eckert number } \\
& \operatorname{Pr}=\frac{v_{f}}{\widetilde{\alpha}_{f}} ; \quad \text { prandtl number }
\end{aligned}
$$

Therefore, when the parameters defined as in Eq. (16) then the Eqs. (11)-(14) possess similarity solutions.

The local shear stresses and heat transfer rate expressed by the following formulas:

$$
\begin{aligned}
& C_{F x}=\frac{\tilde{\tau}_{w}}{\rho_{f} U_{\infty}^{2}} ; \quad \tilde{\tau}_{w}=\tilde{\mu}_{n f}\left(\frac{\partial \widetilde{u}}{\partial y}\right) \text { at } y=0, \\
& N u_{x}=\frac{q_{w} x}{k_{f}\left(\tilde{T}_{w}-\tilde{T}_{\infty}\right)} ; \quad q_{w}=-\left(\tilde{k}_{n f}+\frac{16 \sigma T_{\infty}^{3}}{3 k^{*}}\right)\left(\frac{\partial \tilde{T}}{\partial y}\right) \text { at } y=0,
\end{aligned}
$$

After simplification following version is attained:

$$
R e_{x}^{0.5} C_{F x}=\frac{\widetilde{\mu}_{n f} F^{\prime \prime}(0)}{\mu_{f}}
$$


$R e_{x}^{-0.5} N u_{x}=-\left(\frac{\tilde{k}_{n f}}{k_{f}}+\frac{4}{3 R d}\right) \beta^{\prime}(0)$

Where, local Reynolds number expressed by the following mathematical relation:

$R e_{x}=\frac{U_{\infty} x}{v_{f}}$.

\section{Mathematical Analysis of the Model}

The colloidal models AA7072-Methanol and AA7075-Methanol are nonlinear and tedious system of ODEs associated with multiple conditions based on imposed physical situations. So, it is tough or not even possible to solved the models for closed form solutions. Therefore, the models treated numerically. For said purpose, coupling of RK with shooting technique [18], [19] is implemented. In ordered to apply the algorithm on under consideration colloidal models, first the transformations made for the velocity and temperature equations:

$$
\left.\begin{array}{c}
\tilde{b}_{1}^{*}=F, \tilde{b}_{2}^{*}=F^{\prime}, \tilde{b}_{3}^{*}=F^{\prime \prime} \\
\tilde{b}_{4}^{*}=\beta, \tilde{b}_{5}^{*}=\beta^{\prime}
\end{array}\right\}
$$

Plugging these transformations in model given in Eqs. (11) and (12) we attained the first order colloidal system. Then proposed algorithm is implemented and tackled the model successfully and plotted the results for the flow regimes under multiple physical imposed conditions.

\section{Results and Discussion}

\section{The velocity against Slip Parameter and Suction/Injection}

The velocity of AA702-Methanol and AA7075-Methanol colloidal fluids against the velocity slip parameter is painted in Fig. 2. It is significant to indicate that $f_{w}>0, f_{w}=0$ and $f_{w}<0$, correspond to the local fluid suction, injection and no fluids suction/injection, respectively. It is perceived that the velocity $F^{\prime}(\eta)$ upsurges against the higher values of slip parameter. It is examined that for suction of the fluids, the velocity upsurges abruptly. Physically, in the case of suction more fluid particles drags at the surface and the velocity slip exerts force on the fluid particles; consequently, the velocity upturns abruptly. For injection of the colloidal fluids, increasing behavior of the AA7072-Methanol and AA7075Methanol is quite slow. Physically injection of the fluid disturbs the fluid particles motion at the surface as a result the nanofluids moves slowly in comparison with suction case. For no suction/injection of the fluid $f_{w}=0$, an increment in the velocity is greater than injection and less than suction case. Moreover, it is perceived that boundary layer region increases for suction case; while, declines in the boundary layer is examined for $f_{w}=0$ and injection, respectively. At the surface increase in the velocity is abrupt due to strong slip effects.

The effects of suction/injection on the velocity trends pointed out in Fig. 3. An increasing trend of the velocity are detected against varying suction/injection parameter. The boundary layer thickness drops against the suction case. Physically, for suction case, the fluid particles come closer to each other at the surface which leads to decrement in the boundary layer thickness. While, for injection of AA7072Methanol and AA7075-Methanol, the fluid particles adjacent to the surface moves back as a result the boundary layer thickness starts increasing. Almost similar velocity trends are perceived for AA7072Methano and AA7075-Methanol colloidal suspensions. 


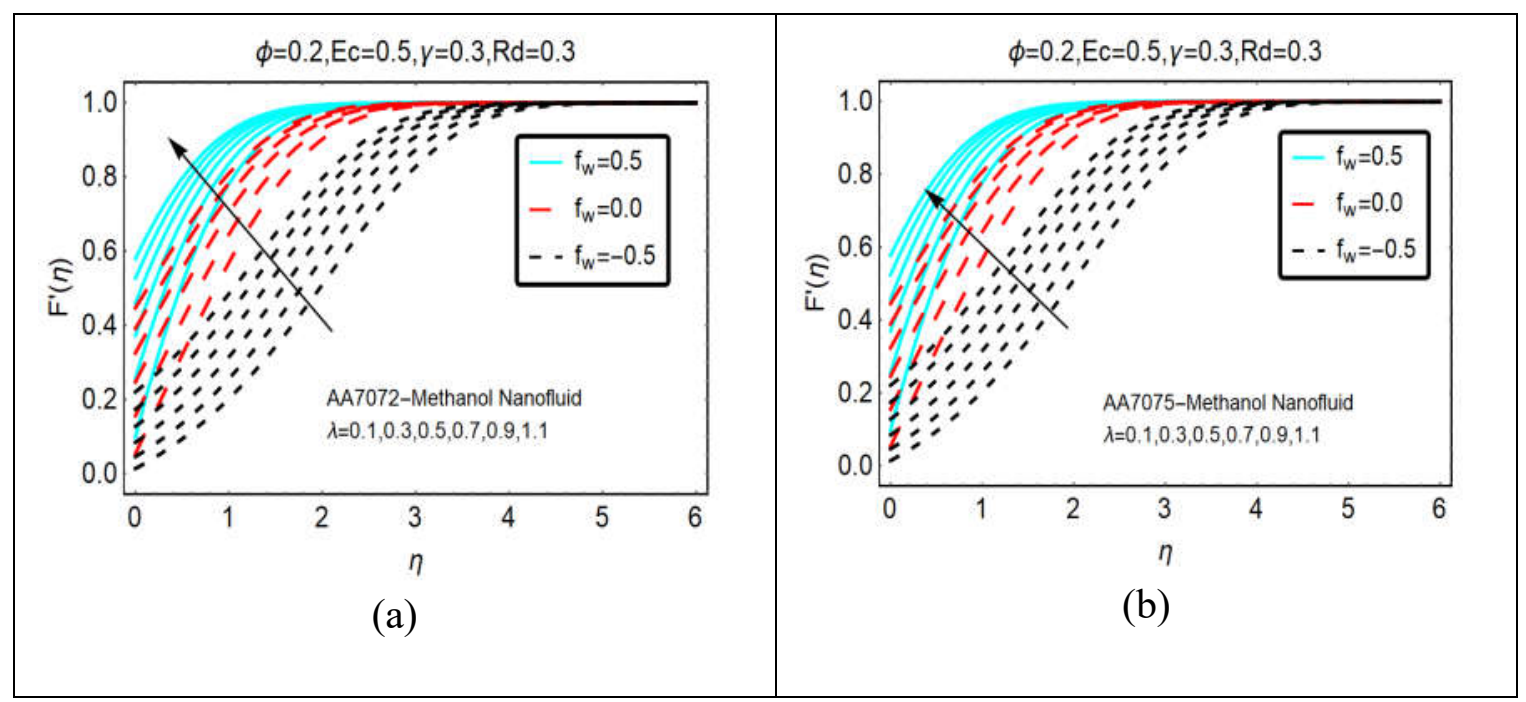

Figure 2: The effects of velocity slip on $F^{\prime}(\eta)$ (a) AA7072-Methanol (b) AA7075-Methanol

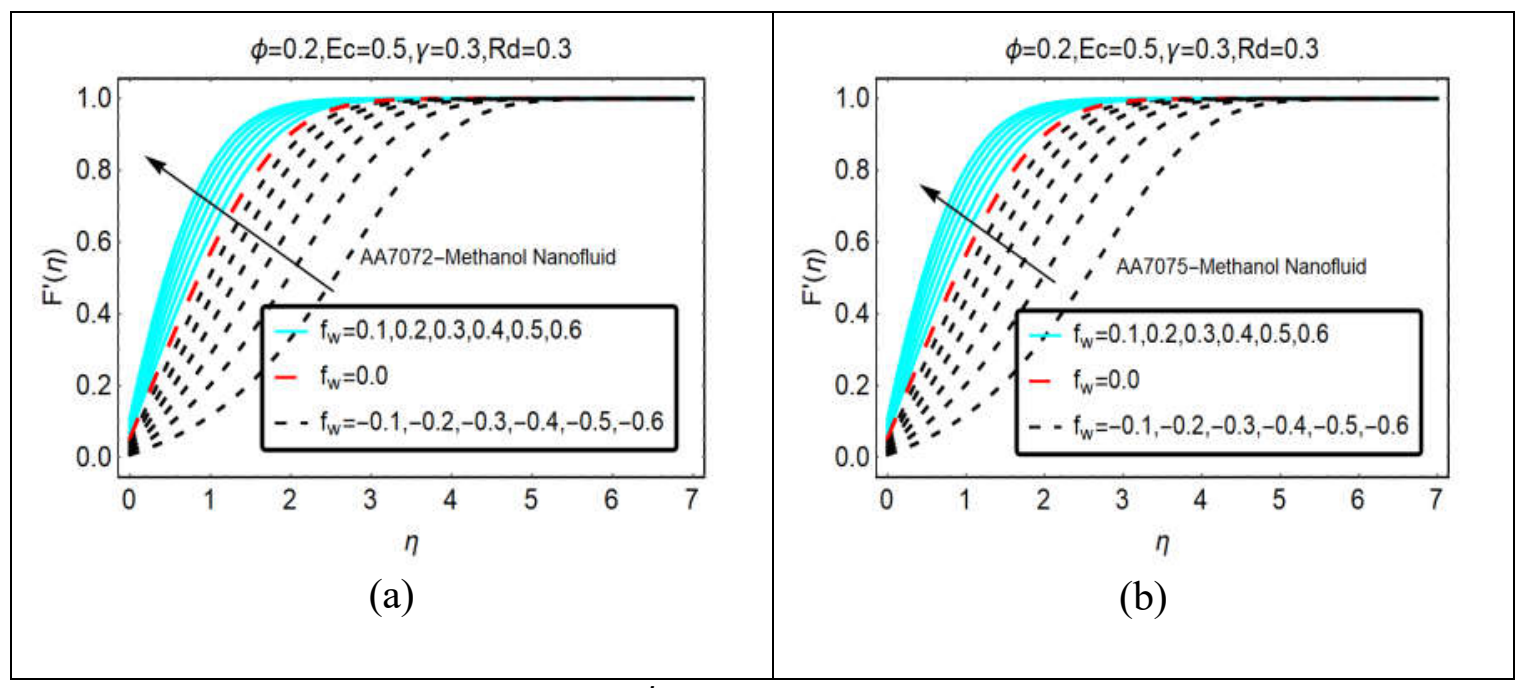

Figure 3: The effects of $f_{w}$ on $F^{\prime}(\eta)$ (a) AA7072-Methanol (b) AA7075-Methanol

\section{The Temperature against Rd and Thermal Slip}

The temperature of AA7072-Methanol and AA7075-Methanol against imposed thermal radiations for heat generation and absorption are decorated in Figs. 4 and 5, respectively. The value $\gamma>0$ and $\gamma<0$ indicates the heat generation and absorption, respectively. It is pointed that the temperature of AA7072Methanol and AA7075-Methanol abruptly enhances for stronger radiation effects in case of heat generation. Physically, the heat energy inside the plate enhances due to heat generation phenomena and more heat energy transfer to the fluid particles; as a result, the temperature rises abruptly. Further, thermal boundary layer thickness rises for suction case. The effects of thermal radiations on the thermal field $\beta(\eta)$ asymptotically vanishes beyond $\eta>10$.

The effects of heat absorption $\gamma<0$ and thermal radiations on the thermal behavior of AA7072-Methanol and AA7075-Methanol painted in Fig. 5. The heat absorption and stronger thermal radiations opposes the temperature. The temperature rapidly declines for suction of the fluids. Further is noted that thermal boundary layer region increases for suction of the colloidal fluids. Near the surface the temperature drops slowly. Physically, these slow decreasing trends in the temperature are due to the stronger radiation 
effects. Apart from the surface, thermal these effects become weaker in the presence of heat absorption. Therefore, abrupt decrement in the temperature $\beta(\eta)$ is detected apart from the surface.

The temperature trends against thermal slip effects are decorated in the presence of heat generation and absorption in Figs. 6 and 7, respectively. For suction of the colloidal fluid, the temperature drops quickly at the surface and these effects become slow apart from the surface. Physically, more fluid particles drag near the surface due to the suction of fluid; which leads to rapid decrement in the temperature $\beta(\eta)$. Furthermore, thermal boundary layer thickness is almost negligible for $f_{w}=-0.4$ and increasing trends in it are detected for suction case. For both AA7072-Methanol and AA7075-Metrhanol almost similar trends in the temperature $\beta(\eta)$ are examined. The temperature pattern for heat absorption and varying thermal slip parameter is captured in Fig. 7. It is noticed that thermal boundary layer region enhances for absorption case than heat generation. Physically, due to heat absorption the energy from the fluid particles transfer at the surface; ultimately the temperature drops abruptly. The decreasing trends in the temperature are almost similar for suction and injection of the colloidal fluids.

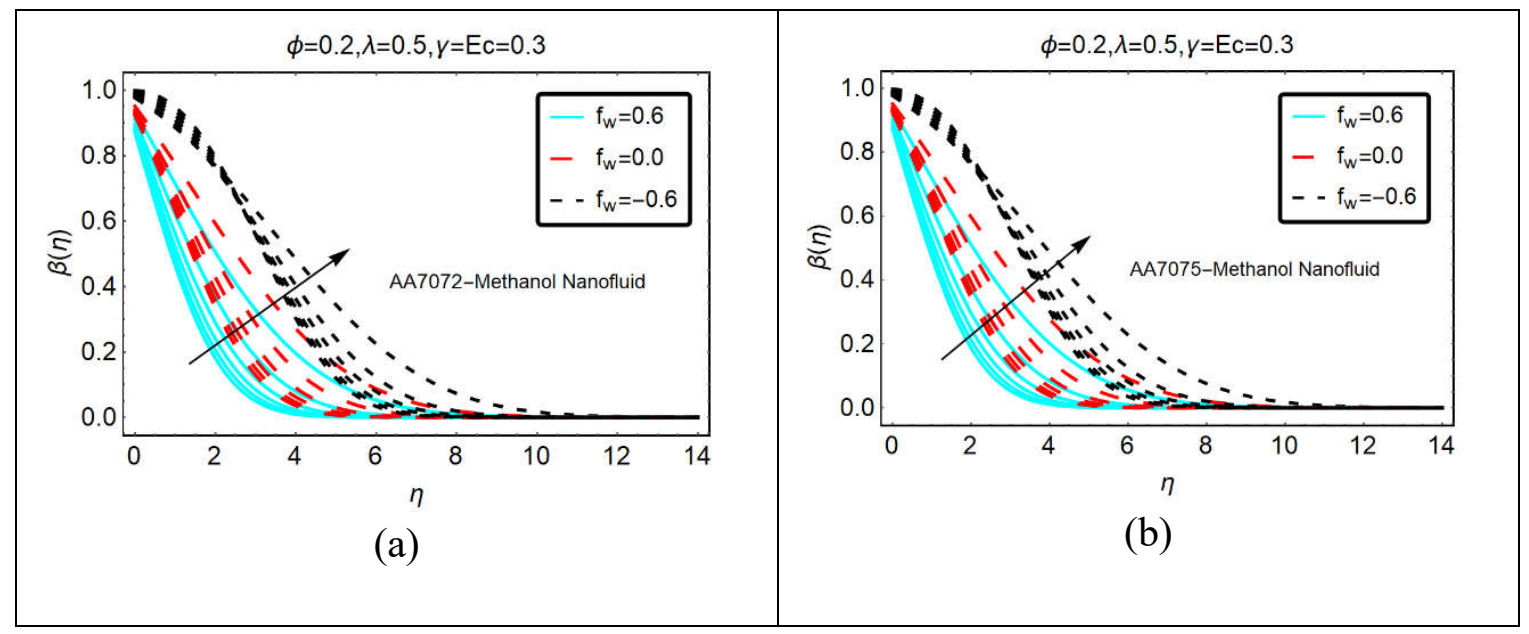

Figure 4: The effects of $R d$ on $\beta(\eta)$ (a) AA7072-Methanol (b) AA7075-Methanol for heat generation

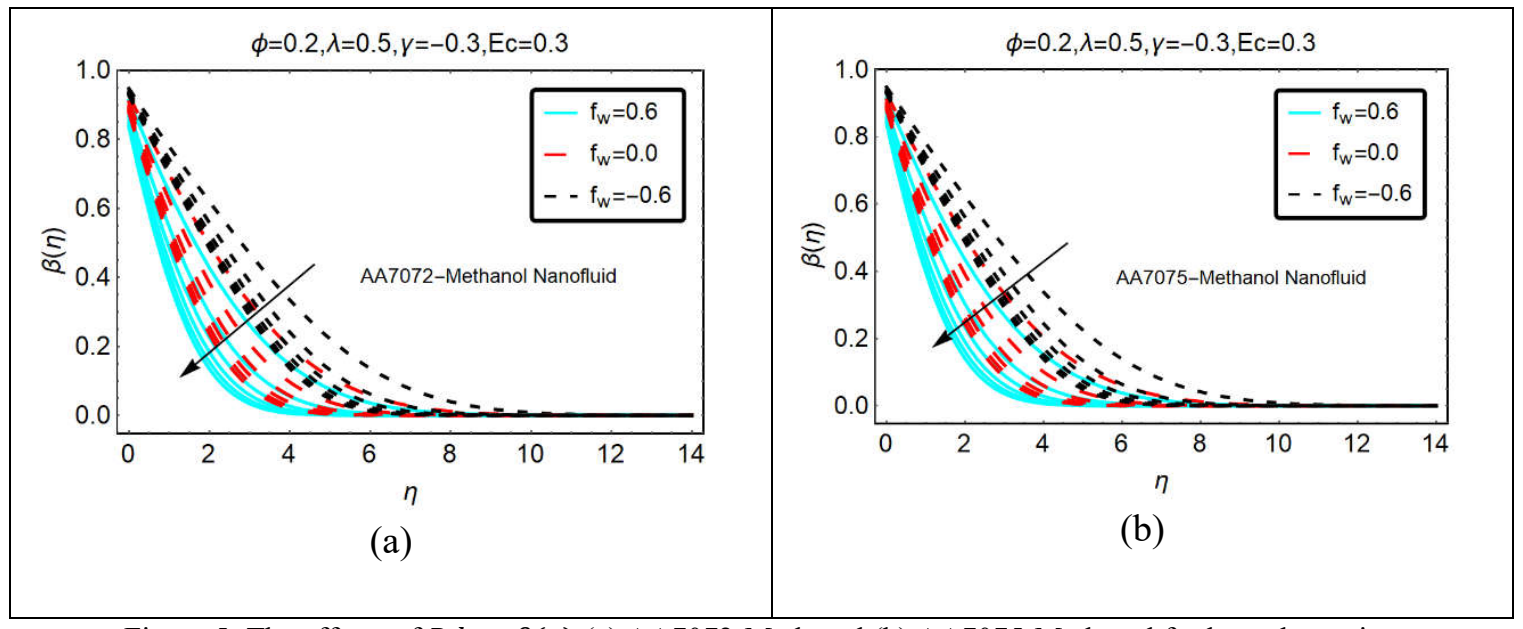

Figure 5: The effects of $R d$ on $\beta(\eta)$ (a) AA7072-Methanol (b) AA7075-Methanol for heat absorption 


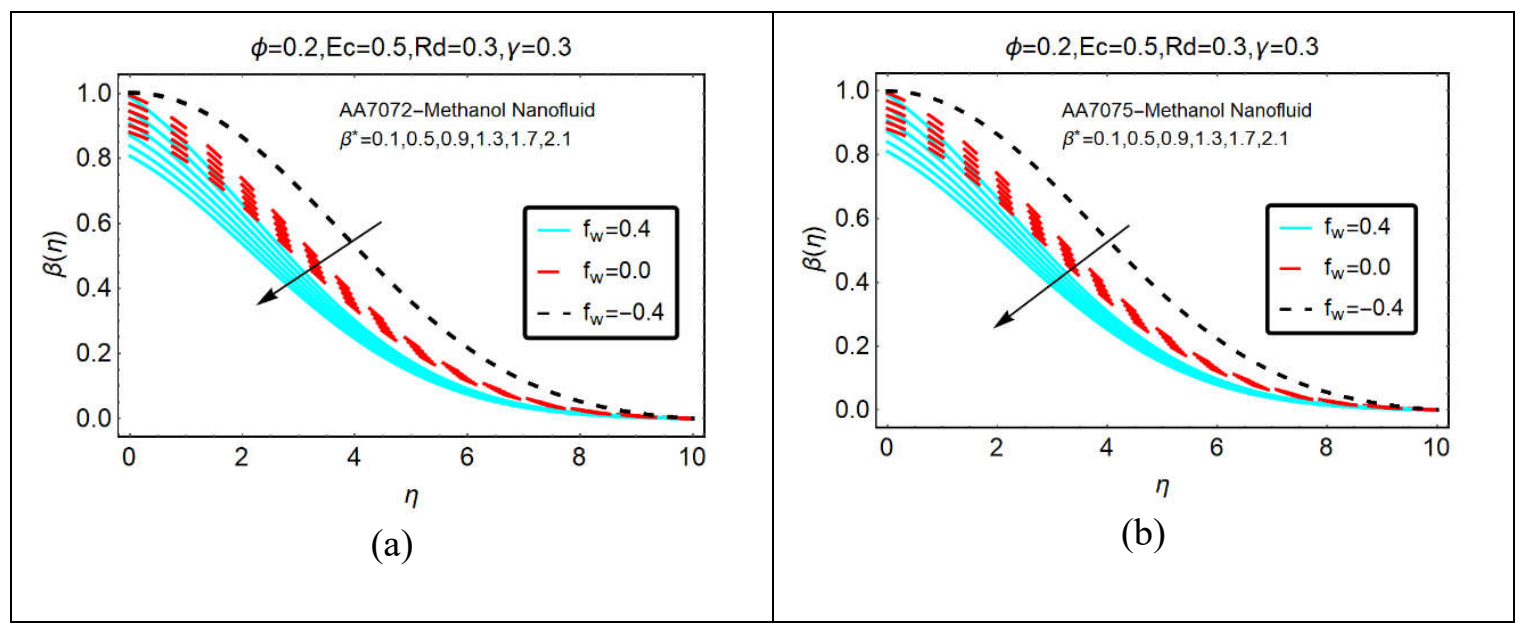

Figure 6: The effects of $\beta^{*}$ on $\beta(\eta)$ (a) AA7072-Methanol (b) AA7075-Methanol for heat generation

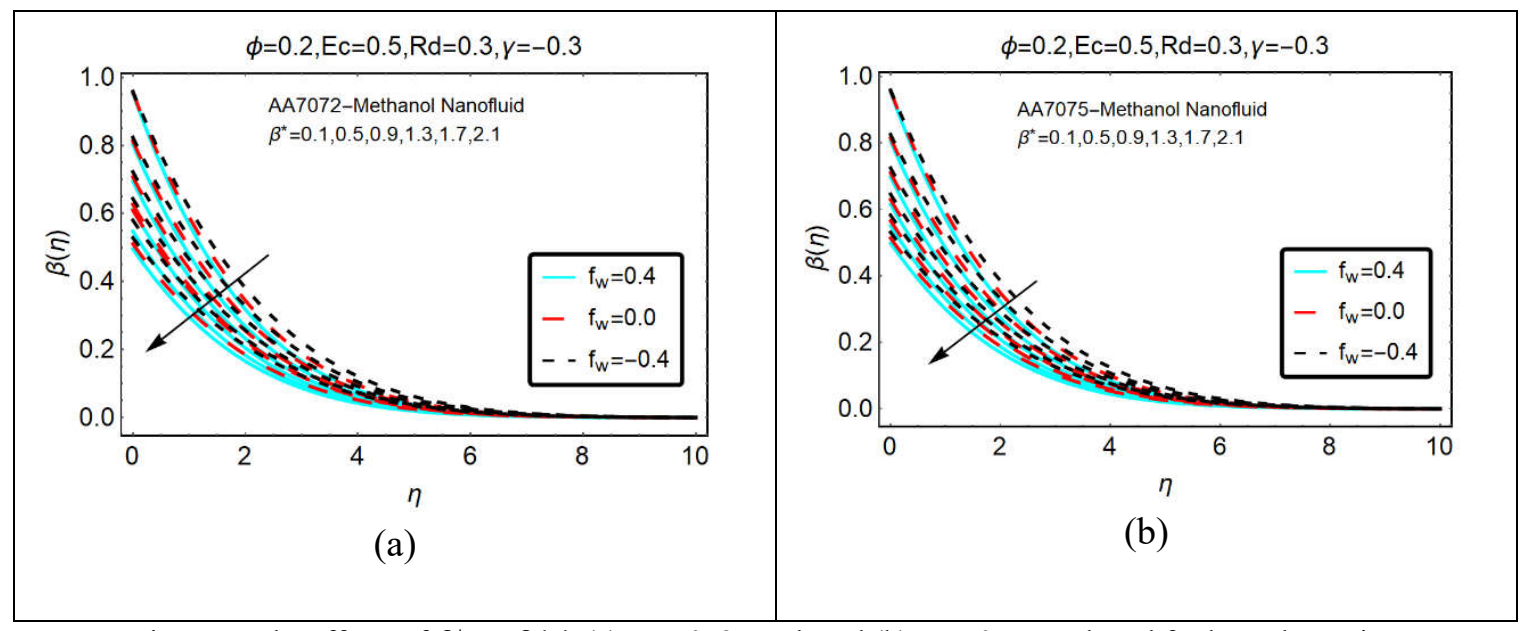

Figure 7: The effects of $\beta^{*}$ on $\beta(\eta)$ (a) AA7072-Methanol (b) AA7075-Methanol for heat absorption

\section{The Temperature against Heat Generation/Absorption and Velocity Slip}

The heat generation effects on the temperature of AA7072-Methanol and AA7075-Methanol are captured in Fig. 8, respectively. It is perceived that the temperature enhances due to stronger heat generation effects. Physically, heat energy rises inside the plate and the energy transfer from the plate to colloidal suspensions particles; consequently, the temperature abruptly enhances. For injection of the fluid, more abrupt increasing trends in the temperature are seen. Physically, injecting the colloidal fluid in the presence of heat generation transfer the energy in the surroundings particles rapidly. Therefore, more rapid trends for injection case are detected and thermal boundary layer thickness increases. Near the surface these trends prevail due to stronger suction and heat generation impacts. On the other side, heat absorption opposes the temperature of AA7072-Methanol and AA7075-Methanol colloidal suspensions. These variations are plotted in Fig. 9.

It is examined that the velocity slip parameter resists the temperature of AA7072-Methanol and AA7075Methanol. These trends are painted in Fig. 10 for both sort of colloidal suspensions. Maximum decrement in the temperature is perceived for injecting fluid. Moreover, thermal boundary layer thickness declines for suction of the fluid. However, decreasing trends in the temperature prevailed for injecting fluid. 


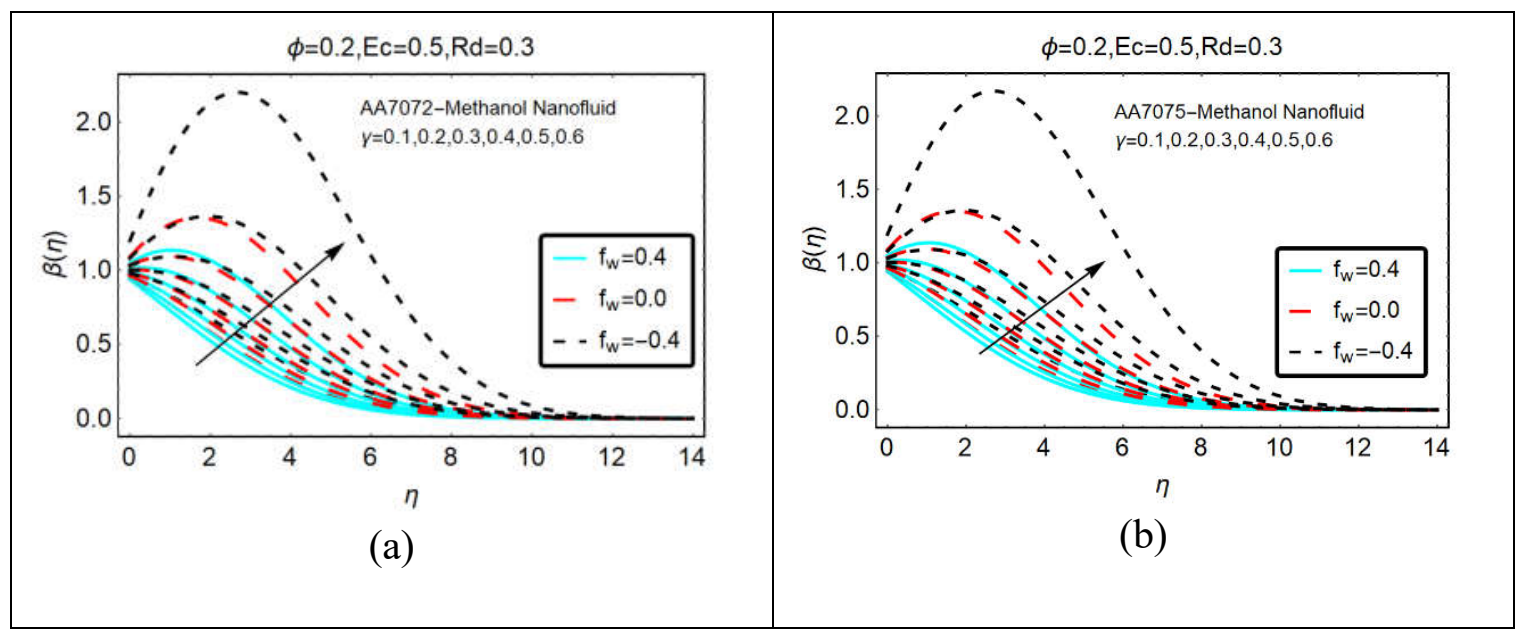

Figure 8: The effects of heat generation on (a) AA7072-Methanol (b) AA7075-Methanol

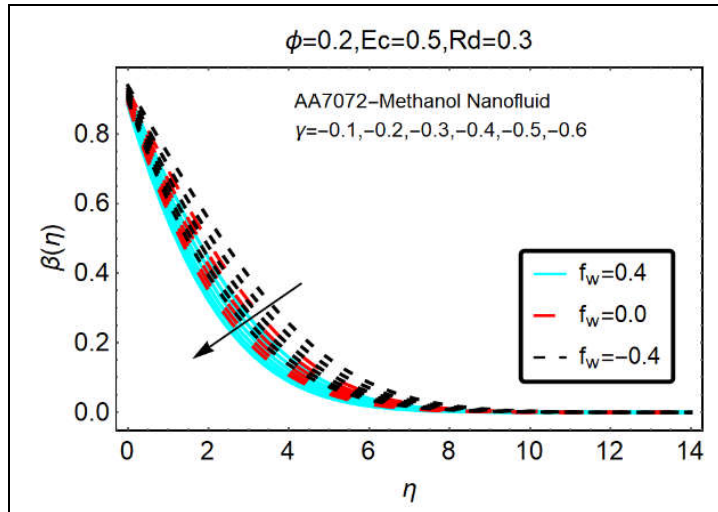

(a)

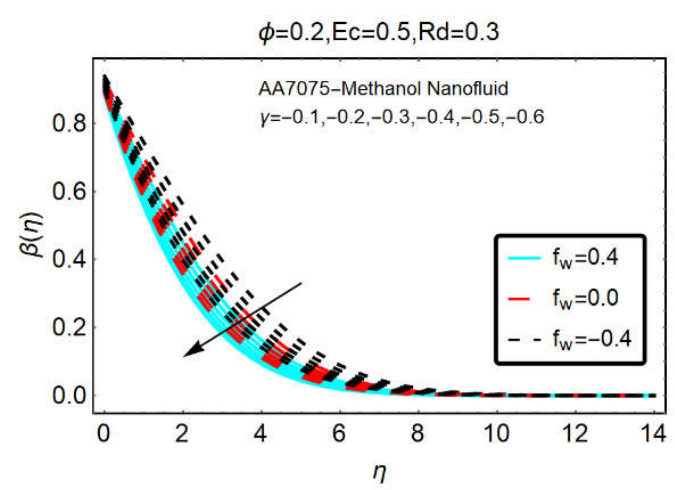

(b)

Figure 9: The effects of heat absorption on (a) AA7072-Methanol (b) AA7075-Methanol

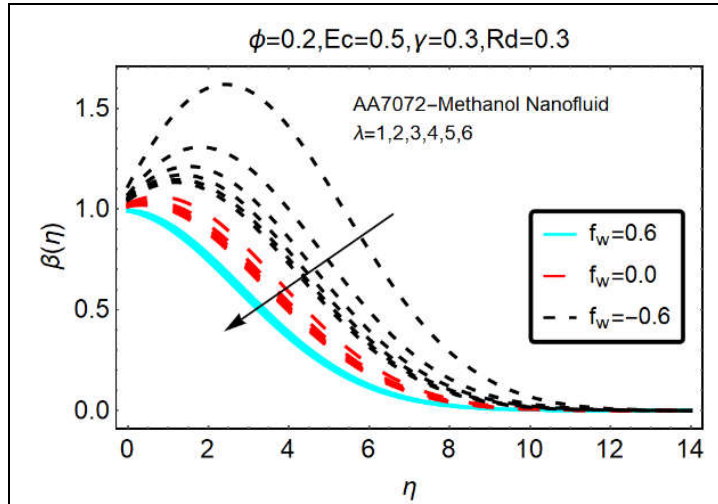

(a)

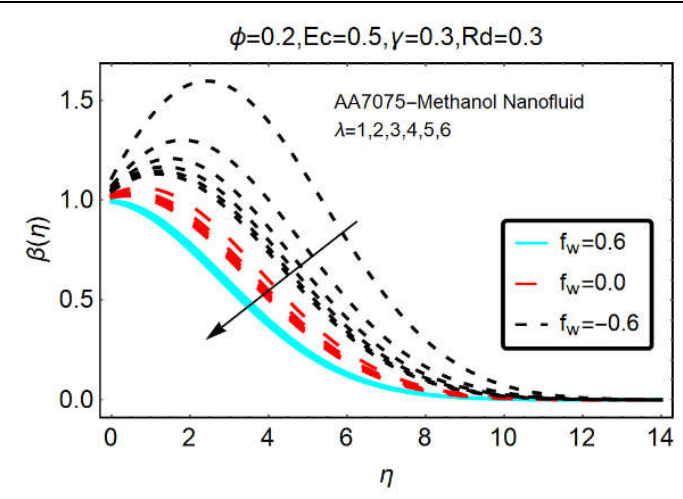

(b)

Figure 10: The effects of velocity slip on (a) AA7072-Methanol (b) AA7075-Methanol 


\section{Shear Stresses and Nusselt Number}

This captured the trends in shear stresses and nusselt number for multiple under consideration flow parameters. It is shown that more shear stresses on the surface are examined for suction of the fluid and stronger velocity slip effects. For injecting of the fluid, these trends become slow. Similarly, for higher velocity slip parameter more heat transfer trends at the surface are detected for suction case. These trends are painted in Fig. 11. The local heat transfer rate against more dissipative fluid and stronger thermal slip effects are plotted in Fig. 12. It is detected that the heat transfer rate at the surface declines for stronger dissipation and thermal slip effects.

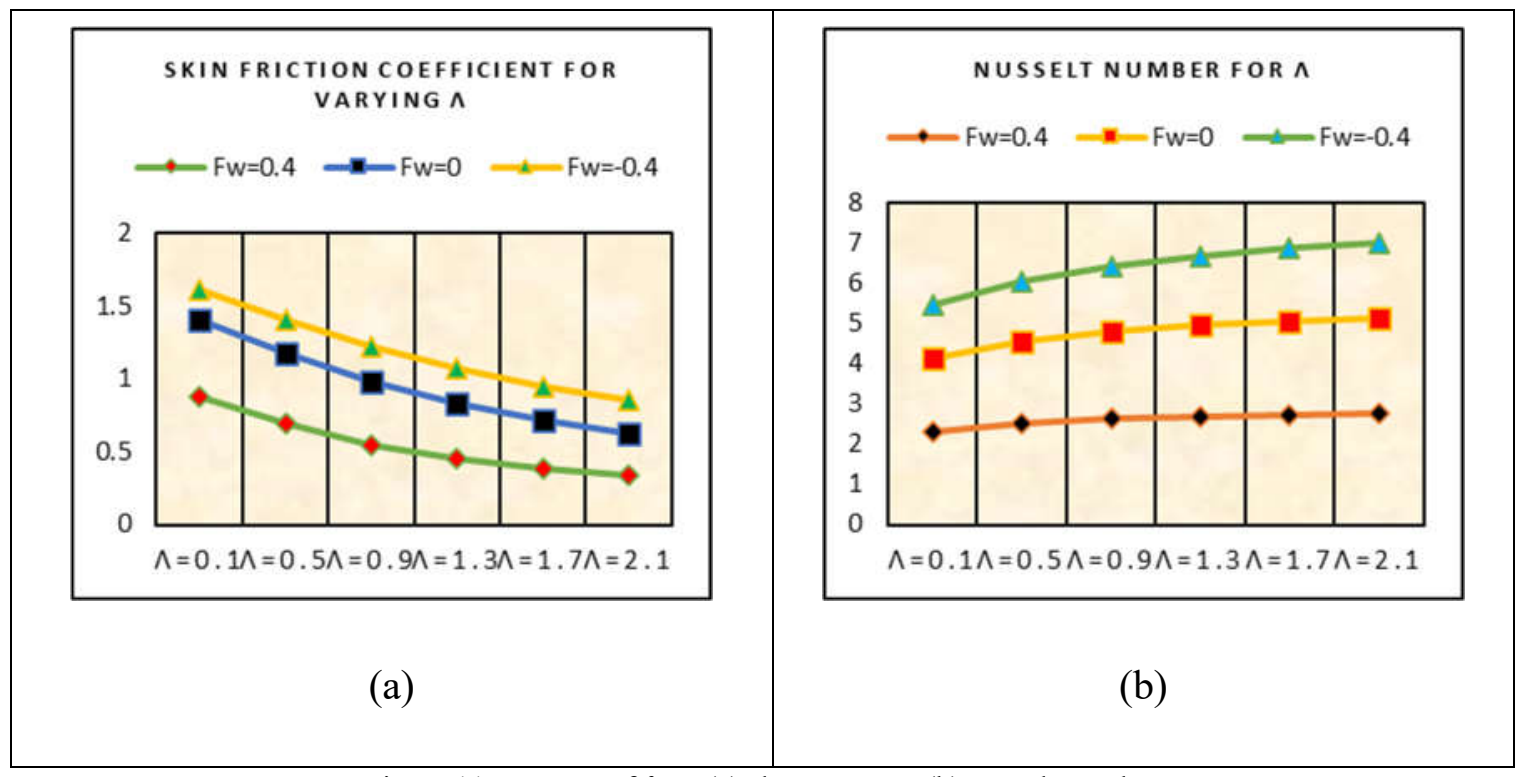

Figure 11: Impacts of $\lambda$ on (a) shear stresses (b) nusselt number

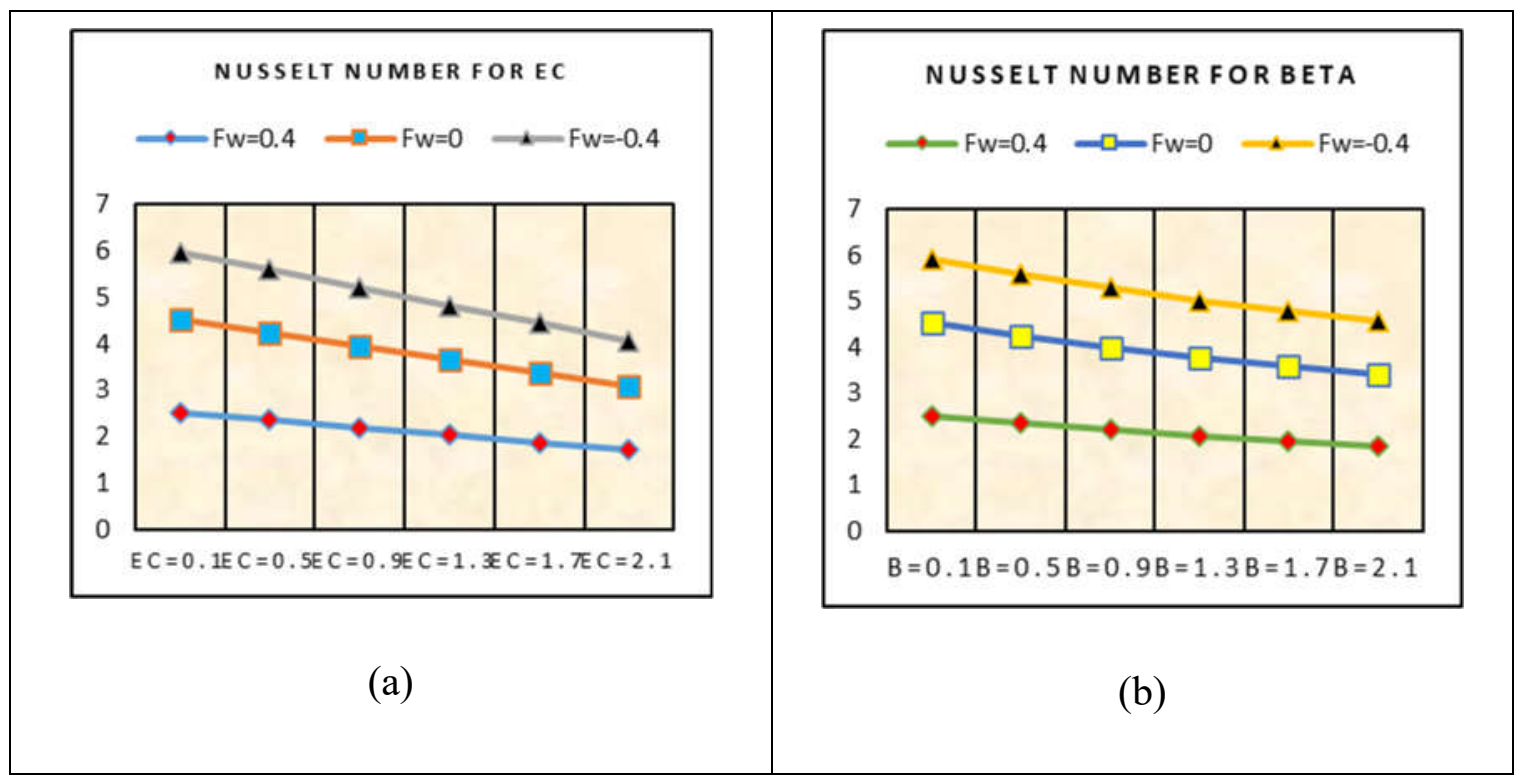

Figure 12: Impacts of (a) Ec (b) $\beta^{*}$ on nusselt number

\section{Conclusions}


The flow of AA7072-Methanol and AA7075-Methanol over a radiative permeable plate under the influence of different physical flow conditions is presented. From the comprehensive discussion of the results, it is concluded that:

- The velocity of AA7072-Methanol and AA7075-Methanol abruptly increases for stronger velocity slip effects and momentum boundary layer thickness declines due to suction of the fluid.

- The temperature of the nanofluids enhances for stronger thermal radiations and heat energy inside the plate; while heat absorption opposes the fluid temperature.

- The temperature effects prevailed throughout the analysis for stronger heat generation in the plate.

- The shear stresses at the surface increases for suction of the fluid because more fluid particles transfer at the surface due to suction.

- The stronger thermal slip effects lead to drops in the local heat transfer rate for both AA7072Methanol and AA7075-Methanol.

\section{Data availability}

The authors declared no additional data for this manuscript.

\section{References}

1. M. R. Hajmohammadi, H. Maleki, G. Lorenzini and S. S. Nourazar. Effects of $\mathrm{Cu}$ and Ag nanoparticles on flow and heat transfer from permeable surfaces. Advanced Powder Technology, 26, 193-199 (2015).

2.A. Ishak. Similarity Solutions for Flow and Heat Transfer over a Permeable Surface with Convective Boundary Condition. Applied Mathematics and Computation, 217, 837-842 (2010).

3. N. A. L. Aladdin, N. Bachok and I. Pop. $\mathrm{Cu}-\mathrm{Al}_{2} \mathrm{O}_{3} /$ water hybrid nanofluid flow over a permeable moving surface in presence of hydromagnetic and suction effects. Alexandria Engineering Journal, 59, 657-666 (2020).

4. B. Mahanthesh, B. J. Gireesha and P. R. Athira. Radiated flow of chemically reacting nanoliquid with an induced magnetic field across a permeable vertical plate. Results in Physics, 7, 2375-2383 (2017).

5. P. D. Prasad, R. V. M. S. S. K. Kumar and S. V. K. Varma. Heat and mass transfer analysis for the MHD flow of nanofluid with radiation absorption. Ain Shams Engineering Journal, 9, 801-813 (2018).

6. H. Maleki, J. Alsarraf, A. Moghanizadeh, H. Hajabdollahi and M. R. Safaei. Heat transfer and nanofluid flow over a porous plate with radiation and slip boundary conditions. Journal of Central South University, 26, 1099-1115 (2019).

7. S. Sadri and M. Babaelahi. Analysis of a laminar boundary layer flow over a flat plate with injection or suction. Journal of Applied Mechanics and Technical Physics, 54, 59-67 (2013).

8. H. Upreti, A. K. Pandey and M. Kumar. MHD flow of Ag-water nanofluid over a flat porous plate with viscous-Ohmic dissipation, suction/injection and heat generation/absorption. Alexandria Engineering Journal, 57, 1839-1847 (2018).

9. Z. Shah, E. O. Alzahrani, W. Alghamdi and M. Z. Ullah. Influences of electrical MHD and Hall current on squeezing nanofluid flow inside rotating porous plates with viscous and joule dissipation effects. Journal of Thermal Analysis and Calorimetry, 140, 1215-1227 (2020).

10. N. Sandeep and I. L. Animasaun. Heat transfer in wall jet flow of magnetic-nanofluids with variable magnetic field. Alexandria Engineering Journal, 56, 263-269 (2017).

11. R. Kandasamy, N. A. B. Adnan, M. Radiah and M. Kamarulzaki. Electric field strength on MHD aluminum alloys (AA7075) nanofluid flow. SN Applied Sciences, (2019).

12. I. Tlili, H. A. Nabwey, G. P. Ashwinkumar and N. Sandeep. 3-D magnetohydrodynamic AA7072AA7075/methanol hybrid nanofluid flow above an uneven thickness surface with slip effect. Scientific Reports, doi:10.1038/s41598-020-61215-8, (2020). 
13. M. Sheikholeslami, T. Hayat and A. Alsaedi. Numerical study for external magnetic source influence on water based nanofluid convective heat transfer. International Journal of Heat and Mass Transfer, 106, 745-755 (2017).

14. M. Sheikholeslami and S. A. Shehzad. Magnetohydrodynamic nanofluid convection in a porous encloure considering heat flux boundary condition. International Journal of Heat and Mass Transfer, 106, 1261-1269 (2017).

15. M. Sheikholeslami. CVFEM for magnetic nanofluid convective heat transfer in a porous curved encloure. The European Physical Journal Plus, (2016).

16. M. Sheikholeslami, D. D. Ganji, M. Gorji-Bandpy and S. Soleimani. Magnetic field effect on nanofluid flow and heat transfer using KKL model. Journal Taiwan Inst Chem Eng, 45, 795-807 (2014).

17. H. Maleki, J. Alsarraf, A. Moghanizadeh, H. Hajabdollahi and M. R. Safaei. Heat transfer and nanofluid flow over a porous plate with radiation and slip boundary conditions. Journal of Central South University, 26, 1099-1115 (2019).

18. U. Khan, Adnan, N. Ahmed and S. T. Mohyud-Din. 3D Squeezed Flow of $\gamma \mathrm{Al}_{2} \mathrm{O}_{3}-\mathrm{H}_{2} \mathrm{O}$ and $\gamma \mathrm{Al}_{2} \mathrm{O}_{3}-\mathrm{C}_{2} \mathrm{H}_{6} \mathrm{O}_{2}$ Nanofluids: A Numerical Study. International Journal of Hydrogen Energy, 42, 24620-24633 (2017).

19. N. Ahmed, Adnan, U. Khan and S. T. Mohyud-Din. Unsteady Radiative Flow of Chemically reacting Fluid over a Convectively Heated Stretchable Surface with Cross-Diffusion Gradients. International Journal of Thermal Sciences, 121, 182-191 (2017).

\section{Competing interests}

There is no financial or competing interest regarding to this research.

\section{Author contributions}

U.K. and A. investigated the model and write original draft, N.A. and S.T.M. methodology and software, A. and N.A. results and discussion, S.T.M. supervision. 
Figures

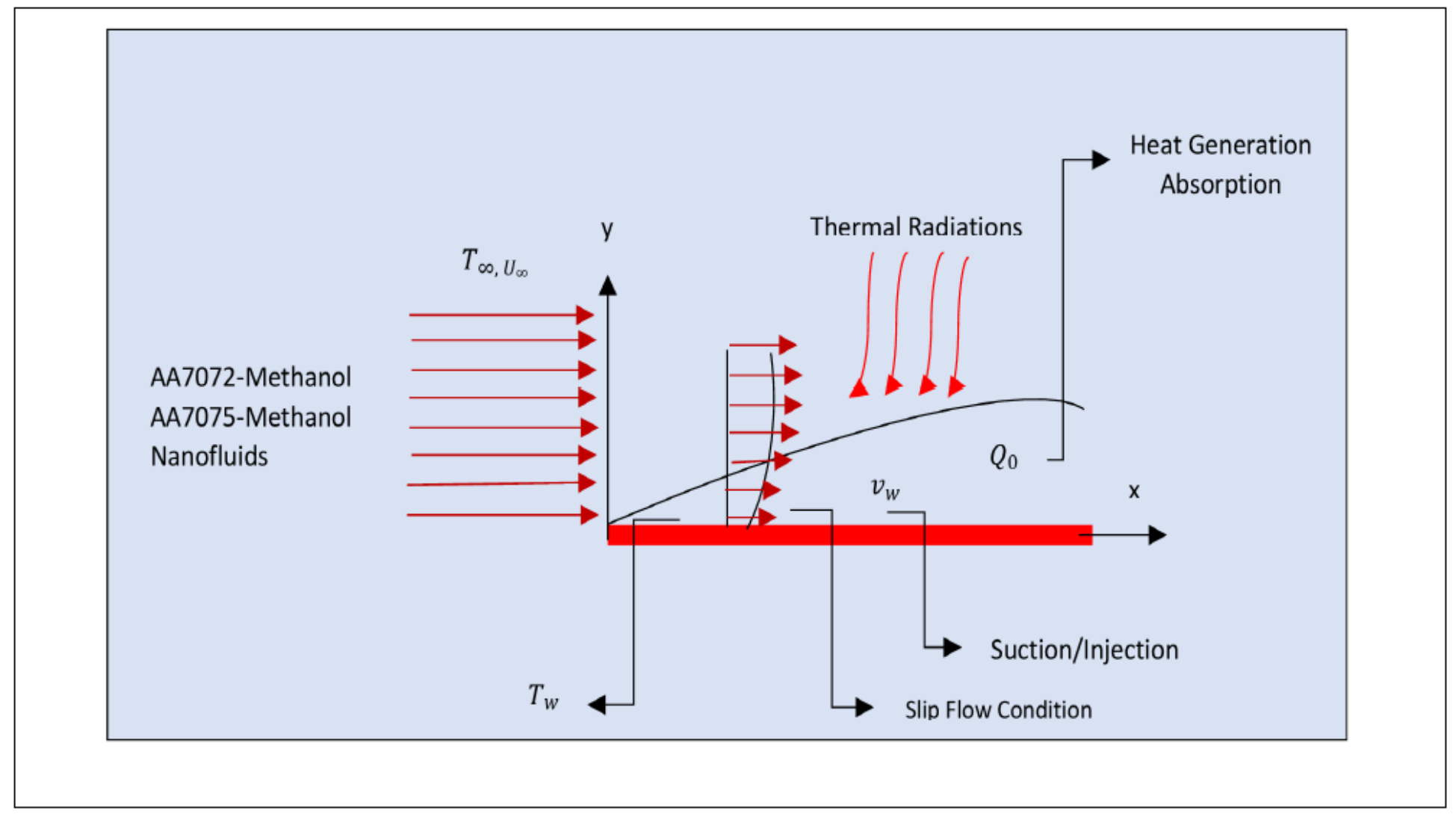

Figure 1

The flow of AA7072-Methanol and AA7075-Methanol over permeable plate

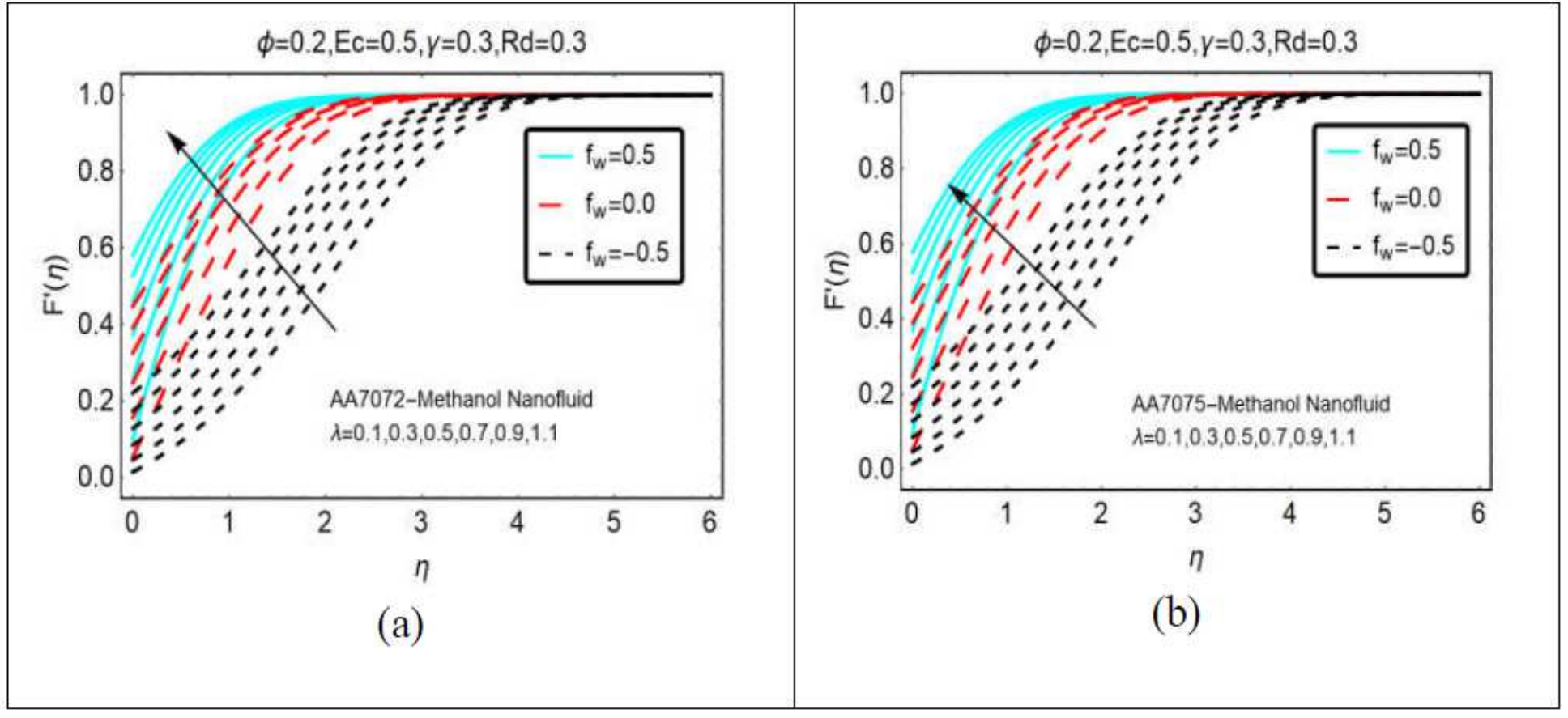

Figure 2 
The effects of velocity slip on $F^{\prime}(\eta)$ (a) AA7072-Methanol (b) AA7075-Methanol

\begin{tabular}{|c|c|c|c|c|}
\hline & \\
\hline
\end{tabular}

Figure 3

The effects of fw on $f^{\prime}(\eta)$ (a) AA7072-Methanol (b) AA7075-Methanol

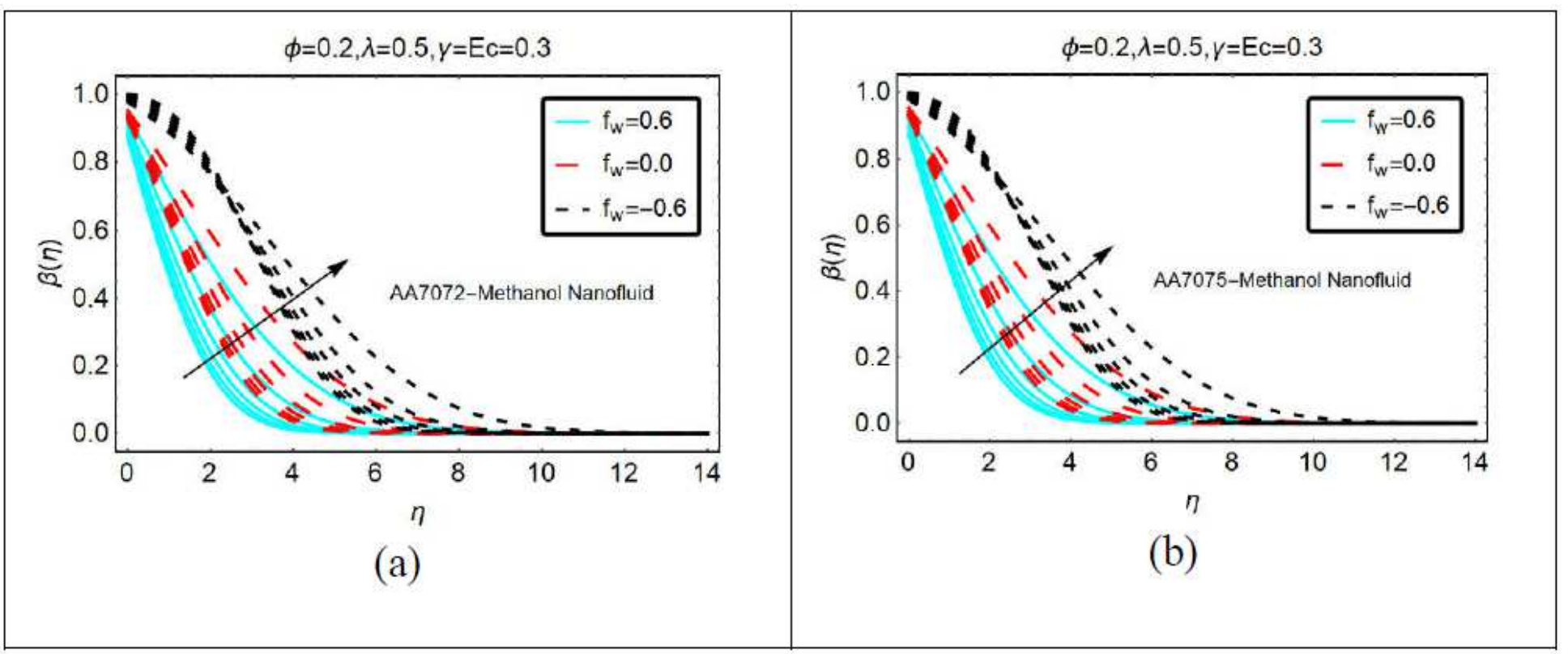

Figure 4

The effects of Rd on $\beta(\eta)$ (a) AA7072-Methanol (b) AA7075-Methanol for heat generation 


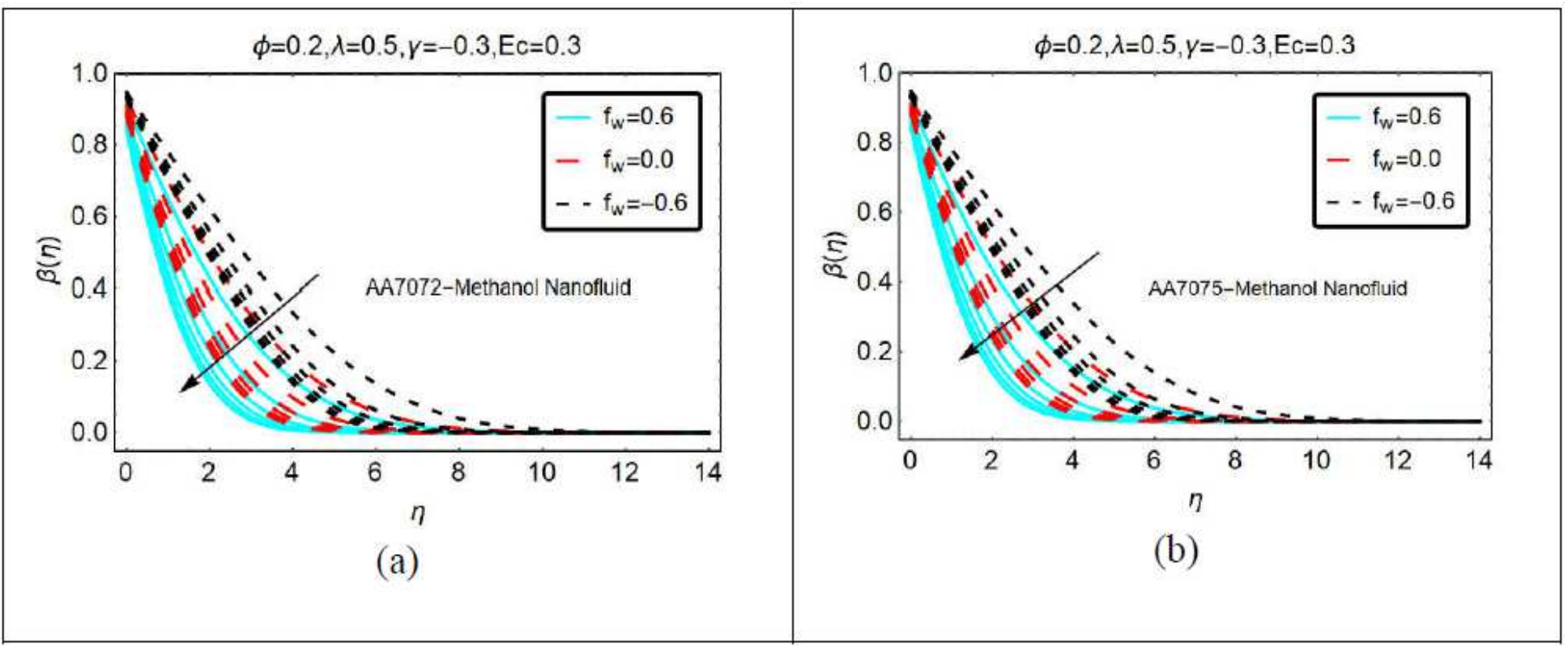

Figure 5

The effects of Rd on $\beta(\eta)$ (a) AA7072-Methanol (b) AA7075-Methanol for heat absorption

$\phi=0.2, \mathrm{Ec}=0.5, \mathrm{Rd}=0.3, \gamma=0.3$
$0.4=0.2, \mathrm{Ec}=0.5, \mathrm{Rd}=0.3, \gamma=0.3$

Figure 6

The effects of $\beta^{\star}$ on $\beta(\eta)$ (a) AA7072-Methanol (b) AA7075-Methanol for heat generation 


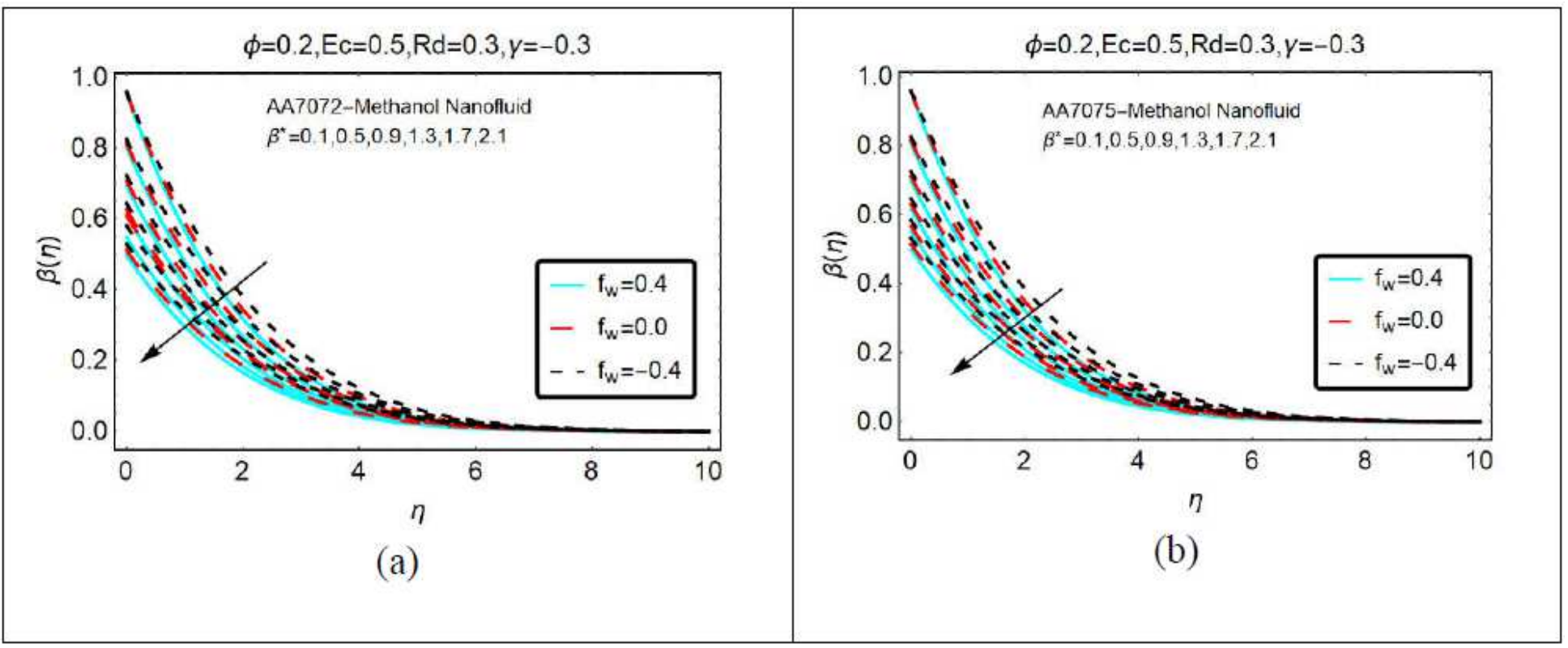

Figure 7

The effects of $\beta^{*}$ on $\beta(\eta)$ (a) AA7072-Methanol (b) AA7075-Methanol for heat absorption

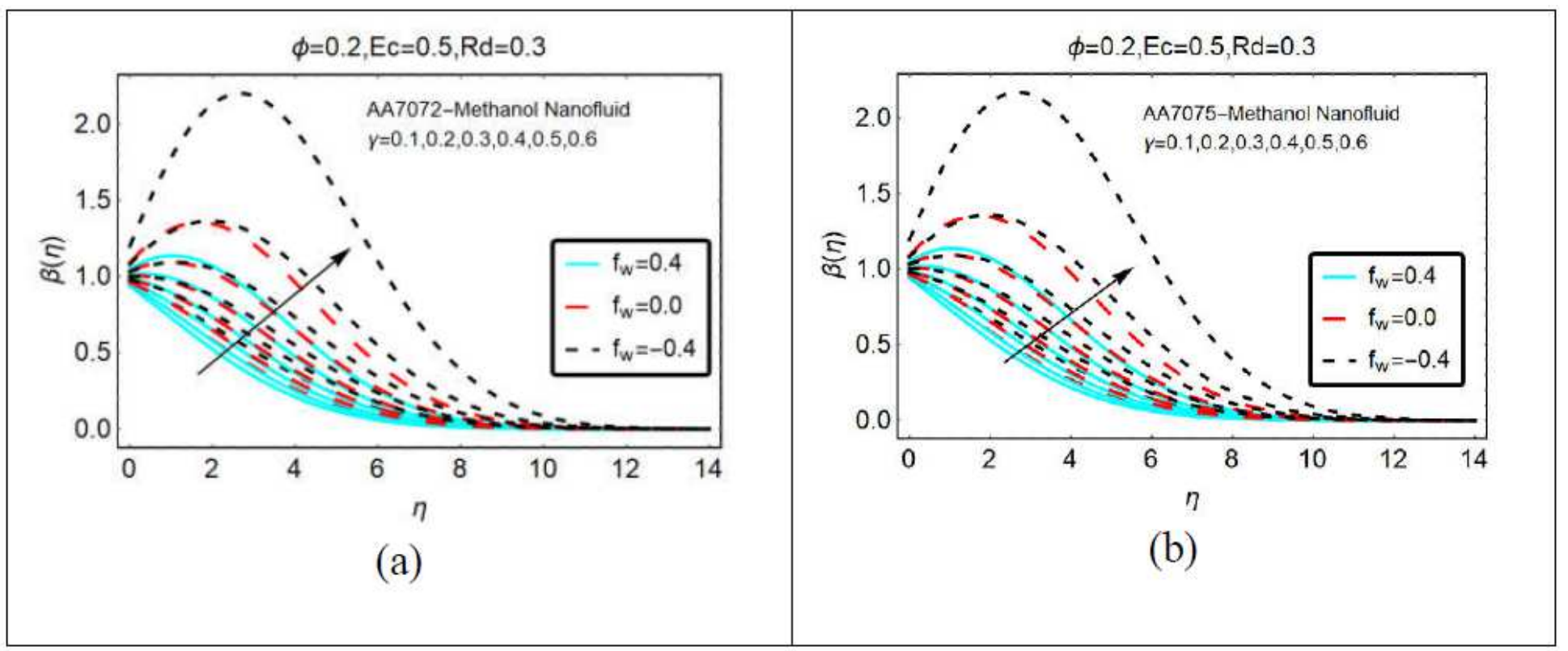

Figure 8

The effects of heat generation on (a) AA7072-Methanol (b) AA7075-Methanol 


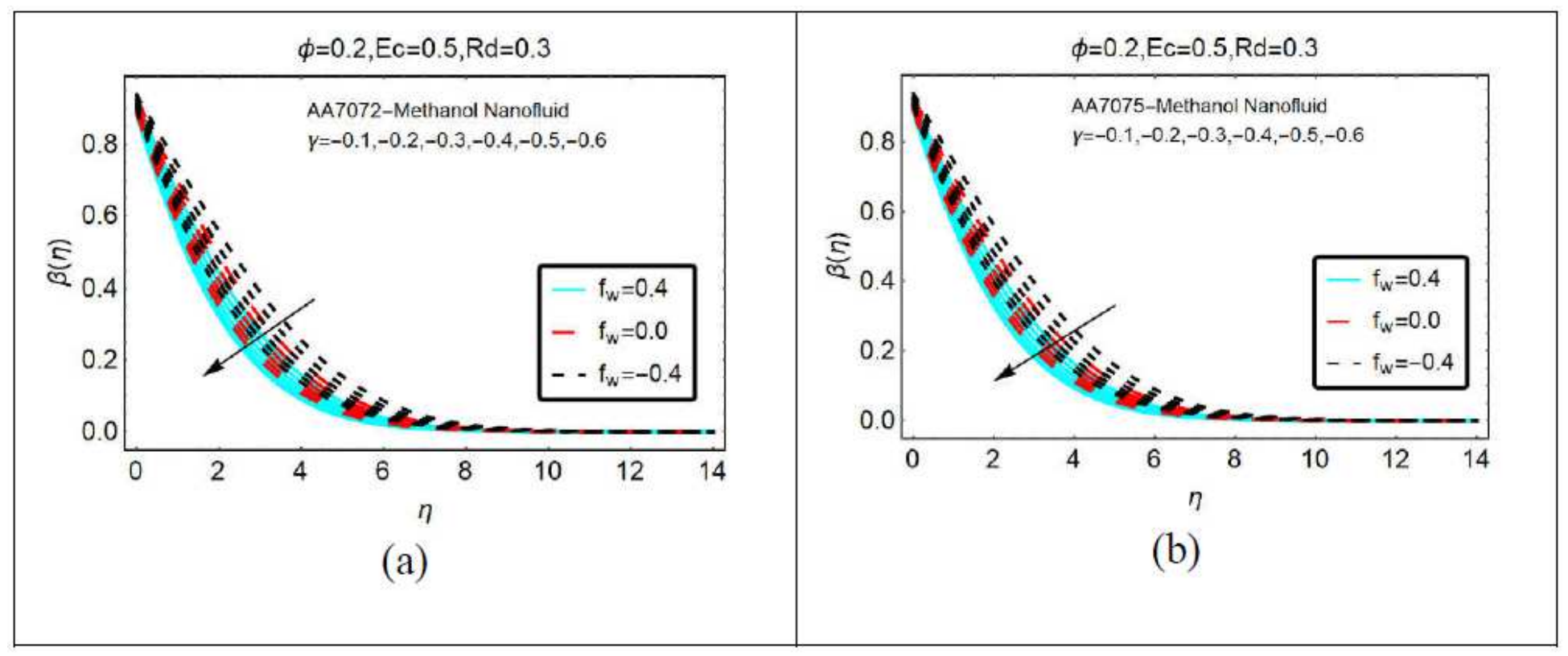

Figure 9

The effects of heat absorption on (a) AA7072-Methanol (b) AA7075-Methanol

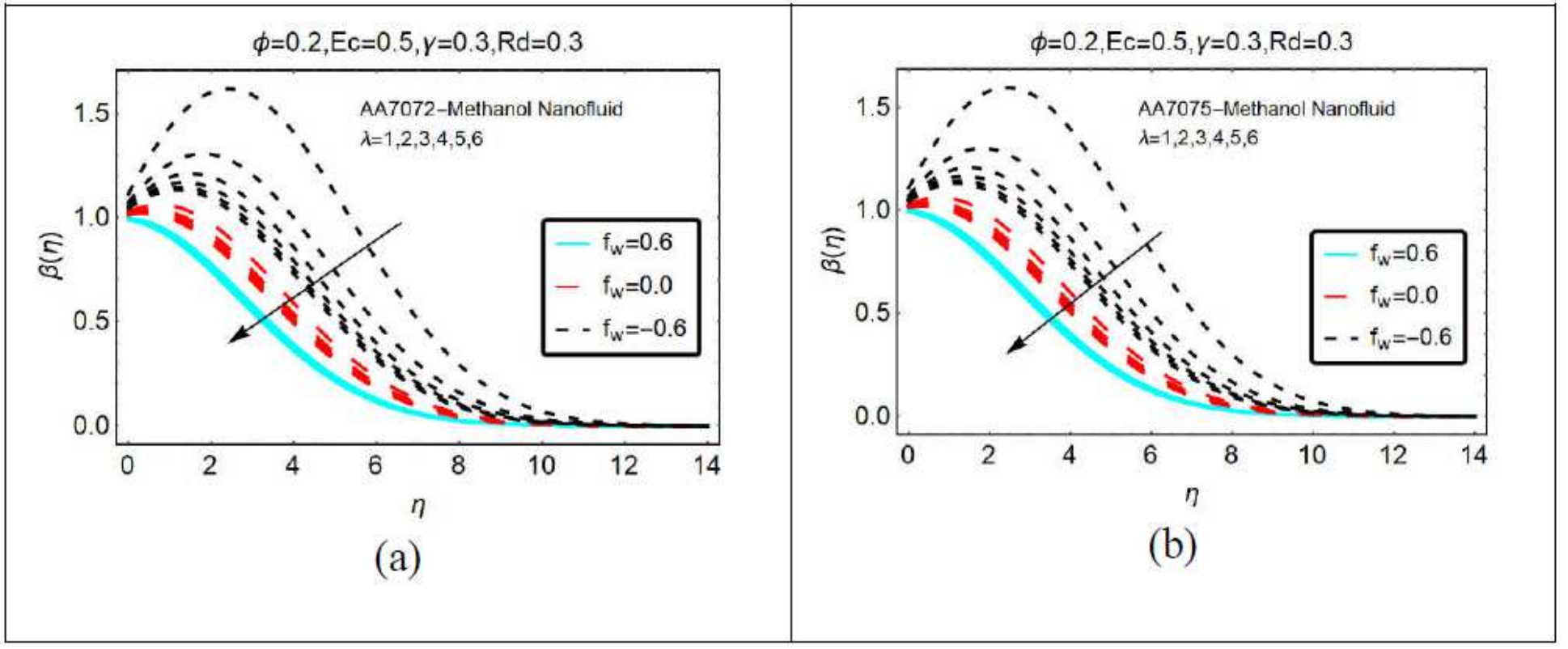

Figure 10

The effects of velocity slip on (a) AA7072-Methanol (b) AA7075-Methanol 


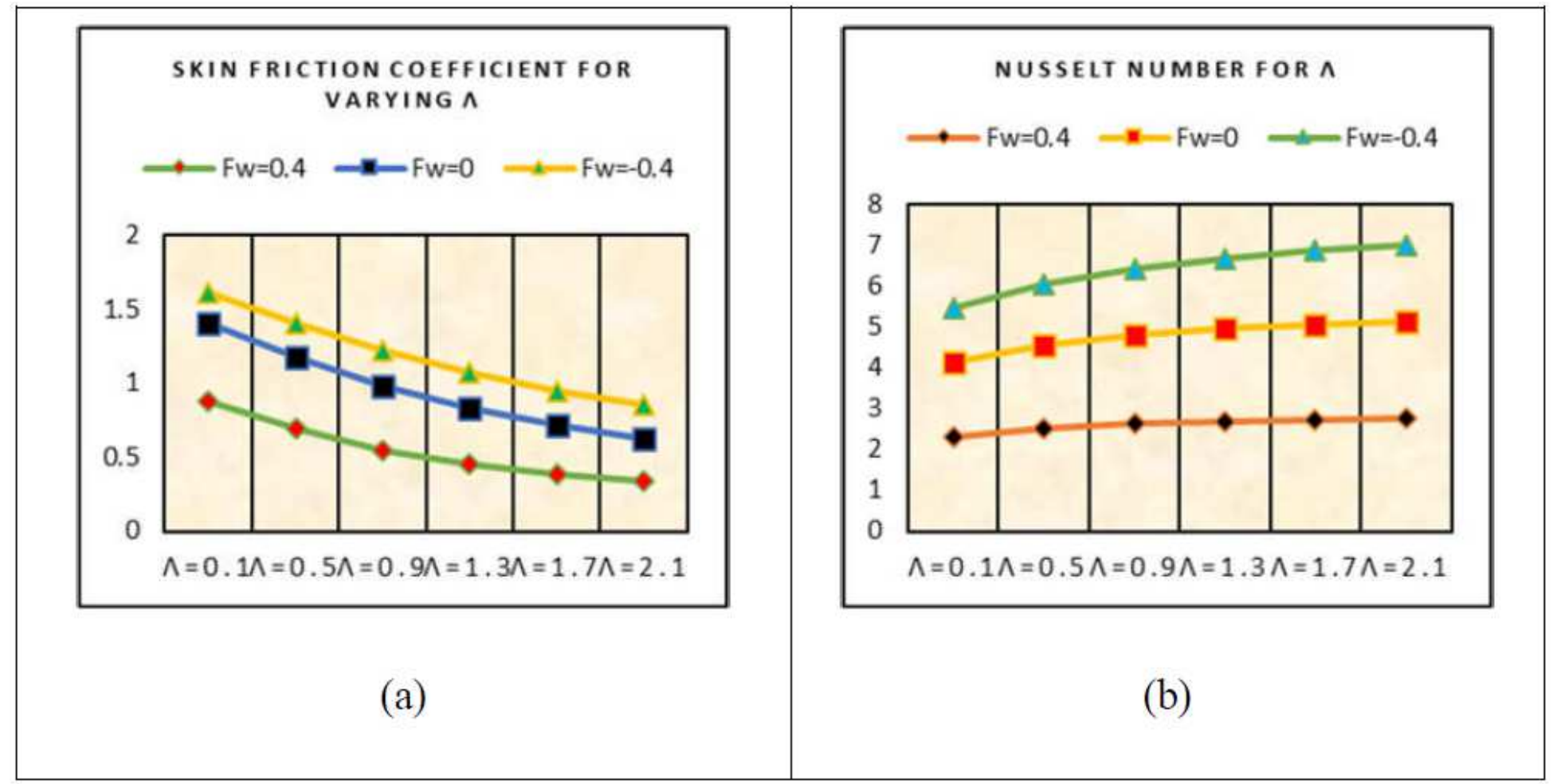

Figure 11

Impacts of $\lambda$ on (a) shear stresses (b) nusselt number

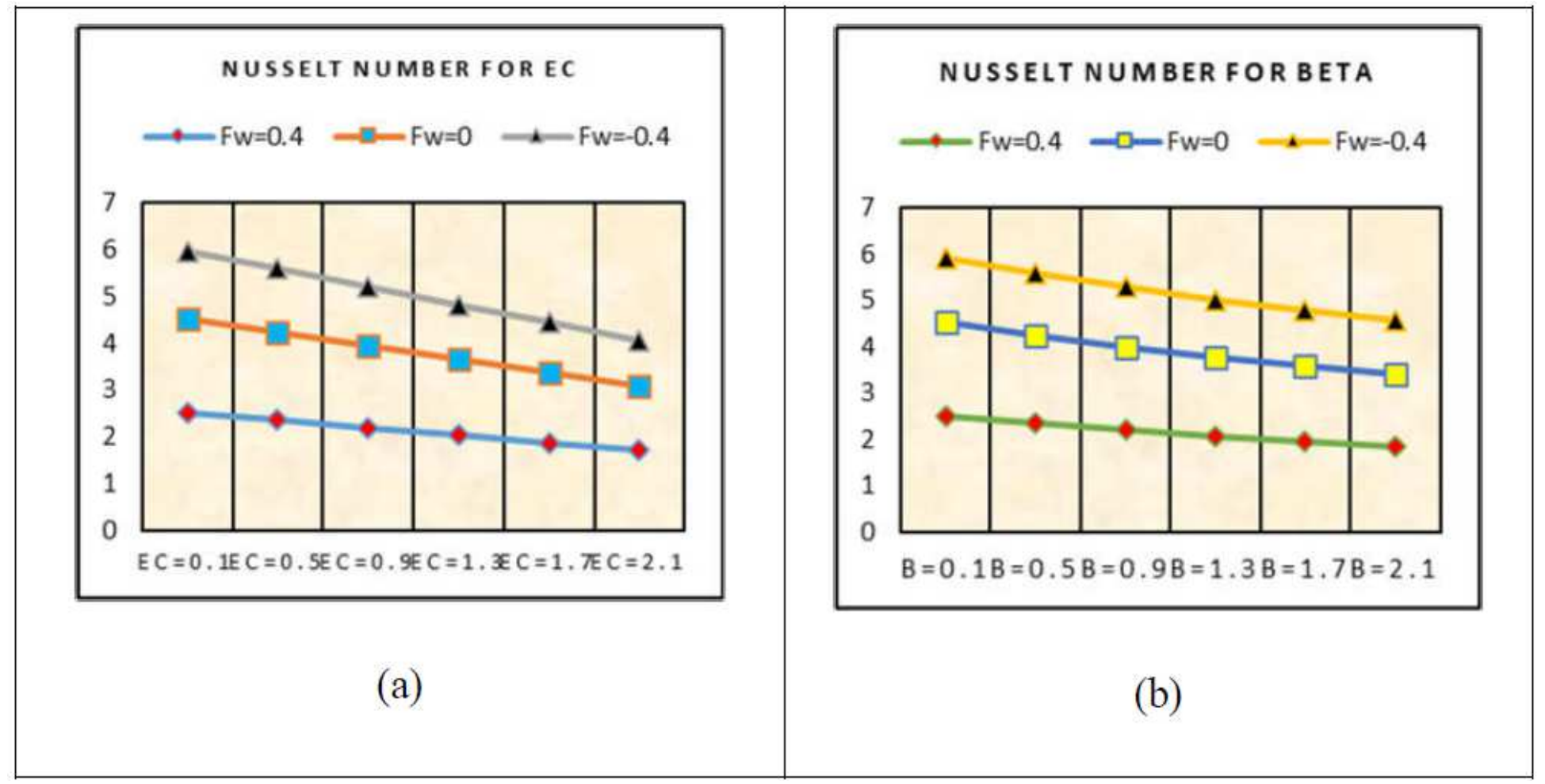

Figure 12

Impacts of (a) Ec (b) $\beta^{\star}$ on nusselt number 